\title{
REPENSANDO AS PRÁTICAS PEDAGÓGICAS A PARTIR DO LETRAMENTO VISUAL E DA ACESSIBILIDADE DAS PESSOAS COM IMPEDIMENTO AUDITIVO
}

\section{Rethinking Pedagogical Practices Based on Visual Literacy and Accessibility for People with Hearing Disability}

\author{
Sandro Medeiros Portella ${ }^{1}$ \\ Luciana da Silva Goudinho ${ }^{2}$ \\ Sérgio Crespo Coelho da Silva Pinto ${ }^{3}$ \\ Ruth Maria Mariani Braz ${ }^{4}$
}

\begin{abstract}
Resumo: As informações chegam maciçamente na sociedade por meio de textos que podem ser falados, escritos, imagéticos e musicais, dentre tantas outras possibilidades. No entanto, preocupa-nos o acesso que os indivíduos com impedimentos auditivos têm às informações em uma sociedade em que a língua majoritária é a língua portuguesa oral e os registros acontecem, prioritariamente, por meio dessa língua oral na modalidade escrita. Refletindo sobre o potencial da escola como ambiente possível de estímulo à aquisição de língua e inserção em práticas sociais, destacamos o letramento visual e o pensamento computacional como importantes ferramentas na escolarização de discentes com impedimento auditivo. Este artigo tem como objetivo considerar o processo de desenvolvimento linguístico e escolar de discentes com impedimentos auditivos, destacando a proposta bilíngue como fator importante desse processo, aliado ao uso de estratégias e materiais didáticos acessíveis. A metodologia utilizada foi a pesquisa exploratória de cunho bibliográfico narrativo, a partir da qual buscamos estudos nas bases científicas e registros acadêmicos sobre o tema. Como resultado, identificamos que as pessoas com impedimento auditivo têm um potencial visual que deve ser estimulado na aprendizagem dos conteúdos. Quanto aos materiais bilíngues para o ensino da pessoa com impedimento auditivo, é imprescindível considerar o uso de imagens em contextos significativos. Por meio desta investigação concluímos que o tempo da imagem é o tempo da palavra, pois exige do professor bilíngue a maneira apropriada de criar diferentes materiais para os discentes, fomentando e apresentando conceitos de maneira que sejam internalizados e externalizados de forma eficaz e com autonomia.
\end{abstract}

Palavras-chave: Educação inclusiva. Acessibilidade. Letramento visual.

\footnotetext{
1 Mestre em Ciência e Biotecnologia, Professor da rede municipal de Niterói; orcid https://orcid.org/0000-0002-8823-0032

2 Doutoranda do Programa de Doutorado em Ciência, Tecnologia e Inclusão da UFF, orcid: https://orcid.org/0000-0003-3925-3366

${ }^{3}$ Professor Adjunto na Universidade Federal Fluminense UFF. Vice-Coordenador do Programa de Doutorado em Ciência, Tecnologia e Inclusão da UFF. Líder do grupo de pesquisa CNPq: Tecnologias Computacionais no ensino e aprendizagem na ótica da Diversidade, Inclusão e Inovação, orcid https://orcid.org/0000-0001-6914-2398

${ }^{4}$ Doutora em Ciências e Biotecnologia pela Universidade Federal Fluminense (UFF), Professor do Curso de mestrado profissional em Diversidade e Inclusão na UFF, orcid: https://orcid.org/0000-0003-2224-9643
} 
Abstract: The information arrives massively in society by means of texts that can be spoken, written, imagery and musical among many other possibilities. However, we are concerned about the access that individuals with hearing disability have to information in a society where the majority language is oral Portuguese and records are primarily through this oral language in written form. Reflecting on the potential of school as a possible environment to stimulate language acquisition and insertion in social practices, we highlight the visual literacy and computational thinking as important tools in schooling deaf students. This article aims to consider the process of linguistic and school development of students with hearing disability, highlighting the bilingual proposal as an important factor in this process, coupled with the use of strategies and accessible teaching materials. The methodology used was exploratory research of a narrative bibliographic nature, where we sought studies in the scientific bases and academic records on the subject. As a result, we identified that people with hearing disability have a visual potential that should be stimulated in the learning of content. As for bilingual materials for teaching the hearing disability, it is essential to consider the use of images in meaningful contexts. Through this research we conclude that image time is the time of the word, as it requires the bilingual teacher to create different materials for the students, promoting and presenting concepts in such a way that they are internalized and externalized effectively and with autonomy.

Keywords: Inclusive education. Accessibility. Visual literacy.

\section{Introdução}

Atualmente, vivemos em uma sociedade globalizada, em que as informações, os valores e os padrões se misturam e se modificam continuamente. A participação consciente é capaz de constituir experiências significativas com o meio social, dependendo do acesso às informações e da capacidade de compreender e ser compreendido em um mundo letrado.

As informações chegam maciçamente na sociedade por meio de textos que podem ser falados, escritos, imagéticos, musicais, dentre tantas outras possibilidades. No entanto, preocupa-nos o acesso que os indivíduos com impedimentos auditivos têm às informações em uma sociedade em que a língua majoritária é a língua portuguesa oral, quando nos referimos ao contexto brasileiro, e os registros acontecem prioritariamente, por meio dessa língua oral na modalidade escrita.

De acordo com Vygotsky (2005), percebemos que a língua, como objeto de comunicação e interação do indivíduo, é de extrema relevância para o desenvolvimento de sua identidade, visto que as variações linguísticas presentes em regiões, classes sociais, ambientes diversos e com particularidades funcionais são fatores pertinentes à forma como o indivíduo desenvolve sua capacidade de interação com o meio.

Assim, tendo em vista os entraves sociais enfrentados por indivíduos com perdas auditivas durante o processo de aquisição de língua de sinais em idade precoce, percebemos que a falta de acesso ao conhecimento e o atraso no desenvolvimento cognitivo em função da ausência de língua para processar o pensamento é preocupante, pois esses indivíduos estabelecem contatos restritos com o meio, impossibilitando a interação com os demais, principalmente familiares.

Segundo Chomsky (apud QUADROS, 1997, p.21), "somos dotados de um aparato neurológico predisposto à aquisição de uma língua, seja ela qual for e de que tipo for". Ao dispor de um aparato neurológico para aquisição de língua, a criança com impedimentos 
auditivos apresenta plenas condições de aprender uma língua de maneira eficiente, desde que essa língua não conte apenas com o feedback acústico fonatório.

Sobre o processo de aquisição linguística dos discentes com impedimentos auditivos, Quadros (2006, p.23) afirma que:

\begin{abstract}
Falar sobre o processo de interações comunicativas, sobre a língua de sinais e sobre a língua portuguesa escrita são formas de desenvolver a conscientização do valor da língua e suas respectivas complexidades. Este exercício dará subsídio para o processo de aquisição da leitura em sinais, bem como para o desenvolvimento da leitura e escrita do português como segunda língua [...]. As crianças surdas precisam internalizar os processos de interação entre o que escreve e o que lê para atribuir o verdadeiro significado da escrita. Dessa forma, a escrita em português é significada a partir da língua de sinais (QUADROS, 2006, p. 23).
\end{abstract}

Sobre essa reflexão podemos afirmar que a dificuldade, no que se refere à língua portuguesa escrita, não está centrada no discente, mas, sim, na falta de formação dos professores para ensinar, adequadamente, tanto a língua brasileira de sinais (Libras) quanto a língua portuguesa com a perspectiva de ensino de uma segunda língua.

A exposição da pessoa com impedimento auditivo ao ambiente escolar sem acessibilidade linguística, sem estratégias adequadas de ensino, deixa esse indivíduo longe da construção de uma identidade, da interação com o outro e do acesso aos conhecimentos valorizados socialmente. É necessário que esses discentes realizem suas atividades em turmas regulares, respeitando as suas singularidades linguísticas, estimulando as suas potencialidades por meio de experiências significativas para que possam fazer leituras de mundo e, consequentemente, se expressar sobre ele. Enfatizamos que o nível de desenvolvimento linguístico de qualquer ser humano estará diretamente relacionado à exposição e às oportunidades de uso de sua língua.

Pettito e Marentette (1991) realizaram uma pesquisa sobre como as crianças adquiriram a linguagem e destacam que não há diferença até os 14 meses de idade, nos balbucios monossilábicos, entre pessoas com impedimento auditivo e ouvintes. Os autores observaram que as crianças têm o mesmo tempo de maturação quando submetidas a um ambiente que as estimule. Contudo, as vocalizações são interrompidas nos bebês que não escutam, assim como as produções manuais são interrompidas nos bebês ouvintes, não por um déficit do aparelho fonador, mas sim devido à falta de estímulos ao desenvolvimento da língua oral. De forma interessante, as crianças ouvintes, filhas de pais que tenham impedimento auditivo, quando estimuladas nas duas línguas, crescem bilíngues. Ou seja, dominam a língua na modalidade oral-auditiva e na modalidade espacial-visual (Quadros, 2004), bem como crianças ouvintes com pais de diferentes nacionalidades adquirem diferentes idiomas.

Pettito e Marentette (1991) e Quadros e Cruz (2011) mencionam que as crianças com impedimentos auditivos balbuciam por meio de gestos, ou seja, manifestam movimentos com as mãos, brincam com as mãos sem, necessariamente, fazerem sinais. Essa é uma indicação de que elas começam a experimentar a comunicação visual, assim como os ouvintes experimentam a voz, portanto apresentam-se dispostos biologicamente à aprendizagem de uma língua, desde que na modalidade adequada. Em geral, grande parte das pessoas com impedimento auditivo, quando filhos de pais ouvintes, enfrenta significativa barreira linguística; desde o nascimento até o momento em que começam a adquirir a língua de sinais, 
as pessoas com impedimento auditivo se encontram isoladas das informações em seu cotidiano e, mesmo após o estabelecimento da língua de sinais, a disponibilidade de informações oferecidas de maneira acessível nos espaços formais ou informais é muito limitada.

Consideramos que, para as pessoas com impedimento auditivo usuárias da Libras língua essa legalmente reconhecida como primeira língua (L1) - e com o português escrito como segunda língua (L2), instiga-nos pensar sobre as possibilidades de aquisição de leitura e escrita dessas crianças em escolas, em que a maioria da comunidade escolar é ouvinte e não domina a Libras. Após aquisição da língua de sinais, a barreira da comunicação é minimizada, mas não totalmente resolvida. Segundo Meireles (2014):

\begin{abstract}
Normalmente, crianças surdas nascem em famílias de pessoas ouvintes onde é utilizada, apenas, a língua oral. Mesmo quando os pais utilizam algum tipo de comunicação visual, esta comunicação é formada por gestos naturais e sinais caseiros convencionados em família. Ainda que a família aprenda a língua de sinais oficial de seu país, ela não será usuária natural não utilizará espontaneamente e, sim, apenas como recurso auxiliar na comunicação com seus filhos (MEIRELES, 2014, p.123).
\end{abstract}

Assim, inquieta-nos considerar as oportunidades de receber informações, compreendê-las e estabelecer relações contínuas com o contexto social. No caso dos discentes com impedimentos auditivos, destaca-se a necessidade de estratégias visuais que viabilizem o acesso às informações e às relações com o meio no qual estão inseridos. Considerando-se que a política em vigor apresenta a possibilidade de escolha entre escolas regulares inclusivas, escolas especiais ou escolas bilíngues de surdos e a maioria dessas crianças vive em famílias ouvintes, preocupa-nos a falta de acesso a uma língua visual que lhes possibilite interação com o meio em que vivem.

Como inserir esse alunado em práticas de letramento se a escola, muitas vezes, não possui profissionais capacitados para estabelecer a comunicação através de uma língua visual? Como estimular a relação dos discentes com impedimento auditivo em práticas sociais se o primeiro desafio estabelecido é o da comunicação? Mas como seriam os materiais pensados para atender à especificidade dos discentes com impedimento auditivo? Quais seriam as estratégias e recursos mais adequados? Qual seria a maneira apropriada de criar e adaptar materiais para discentes com impedimento auditivo?

Diante da Lei Brasileira de Inclusão 13.146/2015, (LBI), coloca-se uma grande questão a ser pensada: Como ocorre o processo de ensino das pessoas com impedimento auditivo? Há acessibilidade às informações, às estratégias e recursos, assim como estruturas pedagógicas adaptadas oferecidas pelos sistemas educacionais? Que estrutura pedagógica vem sendo oferecida a esses discentes para que esse processo se estabeleça? Quais são as possibilidades de promover acessibilidade do conhecimento aos discentes com impedimento auditivo? Buscaremos trazer, ao longo do artigo, propostas para os questionamentos apresentados.

Os saberes acumulados historicamente em nossa sociedade, bem como as notícias, as propagandas, o lazer, e a cultura estão registrados, muitas vezes, de maneira escrita. Faz-se de extrema importância pensar no acesso que o indivíduo com impedimento auditivo terá a esse mundo letrado. Sendo assim, este artigo pretende fomentar questões acerca do letramento visual (OLIVEIRA, 2006), das práticas pedagógicas que o envolvem e da acessibilidade de 
materiais didáticos voltados para a educação desse público. Tendo em vista as reflexões apresentadas, o objetivo deste artigo é refletir sobre o processo de desenvolvimento linguístico que acontece no meio escolar dos discentes com impedimento auditivos, destacando a importância da proposta bilíngue na educação inclusiva.

\section{Metodologia}

A partir desse objetivo, foi realizada uma pesquisa exploratória de cunho bibliográfico narrativo, destacando: Oliveira (2006), Prado e Macedo (2016), Ferreira et al., (2020), Esteves et al., (2020), Quadros (1997; 2004); Quadros e Schmidt (2006); Quadros e Cruz (2011), dentre outros, com a intenção de pesquisar e analisar estudos anteriores e registros acadêmicos sobre o processo de letramento das pessoas com impedimento auditivo. A vantagem dessa opção metodológica, segundo Gil (2002), está na possibilidade de os pesquisadores terem acesso mais amplo ao tema abordado do que ele poderia pesquisar diretamente.

Ao considerar estudos anteriores, temos a possibilidade de elaborar uma análise reflexiva mais abrangente e aprofundada. Dessa forma, procuramos fundamentar a necessidade do letramento visual como fator importante para o desenvolvimento da pessoa com impedimento auditivo levando em conta as estratégias, recursos e adaptações necessárias para que ela tenha acessibilidade aos conhecimentos e possa se desenvolver de forma plena.

Sendo assim, pretendemos alcançar resultados significativos que possam evidenciar o processo de ensino de discentes com impedimento auditivo, considerando: a prática do letramento visual, bem como a acessibilidade às informações, às estratégias e aos recursos, haja vista que as estruturas pedagógicas oferecidas pelos sistemas educacionais não contemplam esses aspectos.

\section{Resultados}

O ensino é um direito de todos e um dever do estado, garantindo que os discentes da rede pública e privada sejam atendidos de forma adequada (BRASIL, 1988). Dentre os direitos previstos por lei, inserem-se as necessidades de adequações curriculares garantindo a acessibilidade e equidade dos conteúdos. $O$ artigo $59^{\circ}$ da Constituição Federal (BRASIL,1988) e a Lei de Diretrizes e Bases - LDB (BRASIL,1996) visam estabelecer diretrizes para o atendimento mais adequado aos discentes que apresentam algum tipo de impedimento, garantindo a igualdade de direitos e de oportunidades para todos num ambiente estruturado para o desenvolvimento do seu processo de aprendizagem.

[...] currículos, métodos, técnicas, recursos educativos e organização específicos, para atender às suas necessidades, terminalidade específica para aqueles que não puderem 4 atingir o nível específico para conclusão do ensino fundamental, em virtudes de sua deficiência, e aceleração para conclusão em menor tempo do programa escolar para superdotados [...] (BRASIL, 1996).

As políticas educativas têm o intuito de contribuir com a oferta de melhorias nas condições de aprendizagem para os discentes, de maneira que possam se sentir acolhidos/confortáveis e recebam as adaptações necessárias de acordo com as suas necessidades educacionais específicas. Nessa perspectiva, a educação inclusiva é pautada na 
Lei de Diretrizes e Bases - LDB (BRASIL, 1996), que determina que o atendimento educacional especializado (AEE) deve ser ofertado às crianças com impedimento auditivo preferencialmente pela escola regular. Para tal, concordamos com Sassaki ao afirmar que o:

\begin{abstract}
processo pelo qual a sociedade se adapta para poder incluir, em seus sistemas sociais gerais, pessoas com necessidades especiais e, simultaneamente, estas se preparam para assumir seus papéis na sociedade. A inclusão social constitui, então, um processo bilateral no qual as pessoas, ainda excluídas e a sociedade buscam, em parcerias, equacionar problemas, decidir sobre soluções e efetivar a equiparação de oportunidades para todos (SASSAKI, 2006, p.3).
\end{abstract}

Sassaki não se remete diretamente à questão escolar, mas sendo a escola parte constitutiva da sociedade tende a refletir em seu cotidiano as questões vivenciadas e apresentadas na sociedade como um todo. Nessa perspectiva, entendemos que ao lidar com as individualidades e o respeito aos direitos no ambiente escolar, estamos investindo no potencial de uma sociedade mais democrática.

A língua possibilita o pensamento e insere o indivíduo em práticas sociais. Portanto, para que a inclusão aconteça, são necessários os direitos linguísticos estabelecidos por Gesser (2009), no que se refere:

[...] à igualdade linguística; à aquisição da linguagem; à aprendizagem da língua materna; ao uso da língua materna; a fazer opções linguísticas; à preservação e à defesa da língua materna; ao enriquecimento e a valorização da língua materna; a aquisição/ aprendizagem de uma segunda língua; à compreensão e à produção plena; de receber tratamento especializado para distúrbios da comunicação; linguísticos da criança surda; linguísticos dos pais de crianças surdas; linguístico do surdo aprendiz da língua oral; do professor surdo e de surdos; linguístico do surdo como indivíduo bilíngue; linguístico do surdo como conferencista; linguístico do surdo de se comunicar com outro surdo (GESSER, 2009, p.84-85).

Quando pensamos em políticas educacionais para as pessoas com impedimento auditivo, é importante levar em conta que a língua de sinais deve ser adquirida como primeira língua, em contato com pares linguísticos, assim, esses indivíduos serão capazes de se relacionar com o mundo e aprenderem uma segunda língua, seja ela qual for, atuando autonomamente na sociedade em que vivem.

No Brasil, a Libras foi reconhecida como meio legal de comunicação e expressão das pessoas com impedimento auditivo, pela Lei $\mathrm{n}^{0}$ 10.436, de 2002 (BRASIL, 2002) e regulamentada pelo Decreto Lei $n^{0}$ 5.626, em 2005 (BRASIL, 2005). É a partir da aquisição da primeira língua/L1(Libras) que a pessoa com impedimento auditivo passa a estabelecer relações com a segunda língua/L2, (língua portuguesa escrita), aprendendo e compreendendo as funções sociais e usos da L2. Como afirma a Lei $\mathrm{N}^{\circ}$. 10.436, podemos destacar a importância do sistema linguístico da Libras:

[...] Língua Brasileira de Sinais (Libras) a forma de comunicação e expressão, em que o sistema linguístico de natureza visual-motora, com estrutura gramatical própria, constitui um sistema linguístico de transmissão de ideias e fatos, oriundos de comunidades de pessoas surdas do Brasil (BRASIL, 2002). 
Assim, a legislação reconhece a língua brasileira de sinais como uma das línguas oficiais, sendo o grande desafio das escolas ter profissionais bilíngues, que dominem a Libras e compreendam a lógica do pensamento da pessoa com impedimento auditivo, para que possam planejar e propor aulas e materiais adequados e significativos.

No caso de um ambiente escolar bilíngue, que proporcione o letramento visual para discentes com impedimentos auditivos, é fundamental a oferta de informações em ambas as línguas (Português e Libras) e em que todos os estímulos, bem como as informações, estejam apresentados de maneira visual, levando em conta que o ambiente precisa ser estimulante e agradável para a interação e o desenvolvimento da aquisição de ambas as línguas simultaneamente.

Com isso, se faz necessário compreender o conceito de bilinguismo com a finalidade de afirmar e esclarecer a importância dessa proposta educacional. A educação bilíngue chega ao Brasil por volta de 1980, no entanto os indivíduos com impedimento auditivo têm o direito garantido por lei de crescerem bilíngues a partir de 2002, por meio do acesso e da utilização de duas línguas oficiais (Libras e Português escrito), para além da aquisição de duas línguas, Fernandes e Moreira (2014, p. 57-58) esclarecem que:

\begin{abstract}
O bilinguismo dos surdos brasileiros constitui uma situação em que a comunidade surda tem um alto grau de identificação com a língua brasileira de sinais (Libras) e a utiliza cotidianamente no encontro surdo-surdo, ou surdo-ouvinte bilíngue. Por sua manifestação se dar por signos visuais (e não orais-auditivos, como na grande maioria das línguas naturais), implica uma constituição de sentidos sobre o mundo diferenciada, forjando uma cultura visual (com produções na arte, na literatura, no humor, na vida social e esportiva...) com impactos que assemelham os surdos a outros grupos étnicos que utilizam línguas minoritárias (como os indígenas, por exemplo). A despeito dessa identificação com sua língua de conforto, a língua portuguesa é a língua oficial do país, pela qual se realizam as interações sociais básicas, desde a família, à escola e o trabalho. Isso impõe a necessidade do uso social do português em ambientes formais, que assume o status de segunda língua para os surdos brasileiros, obrigatório no processo de escolarização dos surdos. Essa situação caracteriza formalmente a condição bilíngue dos surdos brasileiros (FERNANDES E MOREIRA, 2014, p. 57-58).
\end{abstract}

Podemos ressaltar ainda, que as reflexões não devem estar centradas, apenas, na questão linguística, já que o bilinguismo requer representação política, cultural e social. De acordo com Meireles (2014, p.90):

\footnotetext{
Apesar de movimentos educacionais modernos apontarem na direção de uma educação bilíngue para surdos, essa educação não pode ser definida, apenas, como sendo o desenvolvimento de habilidades linguísticas em duas ou mais línguas. Educar é um ato político e a educação bilíngue para surdos é fundamental também para o desenvolvimento da consciência política para entender a educação de surdos como uma efetivação de direitos humanos. Os projetos de educação bilíngue não devem se restringir à utilização de duas línguas, como uma "tolerância" ao uso de uma língua minoritária. Mas, antes devem se constituir como políticas públicas de educação e afirmação dos direitos humanos (MEIRELES; 2014, p.90).
} 
Dessa maneira, devemos entender que a educação bilíngue de discentes com impedimento auditivo é uma construção histórica, social e cultural de práticas discursivas e não discursivas e de seus processos educativos. A educação bilíngue precisa ser entendida e colocada em prática como um posicionamento político de representação da comunidade das pessoas com impedimento auditivo, usuários da Libras, e de resistência às ideologias dominantes e das políticas públicas de educação voltadas para a homogeneização dos indivíduos.

Segundo Xavier et al. (2016), a "educação de Surdos é educação. E como toda a educação, não pode ser finita! Não pode ser um fim em si mesma. Ela é o meio. O meio de trazer autonomia, equidade, empoderamento do sujeito Surdo" (XAVIER et al., 2016, p.33). Logo, a escola se torna o lugar que pode impulsionar e oferecer a autonomia para as pessoas com impedimento auditivo, desde que esteja equipada com as ferramentas e profissionais necessários para realizar esse movimento.

Diante da atual política nacional de inclusão, a Lei Brasileira de Inclusão (2015), em que a ênfase é dada a matricular esses discentes em escolas regulares, preocupa-nos a acessibilidade linguística e organizações pedagógicas que possibilitem o seu desenvolvimento linguístico adequado. De acordo com Glat e Blanco (2007, p.16), o movimento de inclusão escolar prevê mais do que o simples cumprimento de leis. Para elas, a educação inclusiva:

\begin{abstract}
Significa um novo modelo de escola em que é possível o acesso e permanência de todos os discentes e onde os mecanismos de seleção e discriminação, até então utilizados, são substituídos por procedimentos de identificação e remoção de barreiras para a aprendizagem. [...] mais do que uma nova proposta educacional, a Educação Inclusiva pode ser considerada como uma nova cultura escolar (GLAT; BLANCO, 2007, p.16).
\end{abstract}

A sua inserção em práticas sociais de letramento vai depender da acessibilidade visual que for oferecida na escola, na família e na sociedade como um todo, ou seja, através das interações sociais formais e informais. Baseando-se na premissa de que toda imagem pode ser lida, podemos nos reportar ao letramento visual, caracterizando-o como a habilidade de entender e interpretar as informações visualmente. Segundo Oliveira (2006):

\footnotetext{
O letramento visual é a área de estudo que lida com o que pode ser visto e como se pode interpretar o que é visto. É abordado a partir de várias disciplinas que buscam: estudar os processos físicos envolvidos na percepção visual; usar a tecnologia para representar a imagem visual; desenvolver estratégias para interpretar e entender o que é visto (OLIVEIRA, 2006, p.27).
}

Diante das possibilidades e definições de letramento, podemos entender que este se caracteriza como uma prática social de leituras e/ou escritas. Soares (2005) confirma isso, mencionando que o conceito não deve ser visto como um conjunto individual de habilidades, mas sim como práticas sociais que se relacionam com a leitura e a escrita, envolvendo os contextos sociais dos sujeitos. De acordo com Soares (2016):

[...] letramento é o que as pessoas fazem com a habilidade de leitura e de escrita, em um contexto específico, e como essas habilidades se relacionam com as 
necessidades, valores e práticas sociais. Em outras palavras, letramento não é pura e simplesmente um conjunto de habilidades individuais; é o conjunto de práticas sociais ligadas à leitura e à escrita em que os indivíduos se envolvem em seu contexto social (SOARES 2016, p.72).

A maioria das pessoas em nossa sociedade não domina a língua de sinais e as fontes de informações como a televisão, o rádio, jornais, revistas, entre outras, não estão totalmente acessíveis a todos. Atualmente, observamos que desde muito cedo as crianças, de um modo geral, são expostas às mais variadas tecnologias de informação e comunicação (TIC), imersas em culturas digitais, pelas quais utilizam diariamente smartphones, tablets, aplicativos, câmeras, jogos, dentre outras tecnologias, e mostram tamanha naturalidade ao vivenciarem um universo constantemente conectado, onde fazem uso dessas ferramentas tecnológicas para terem acesso à cultura, entretenimento, aprendizagem e comunicação. Além de relacionar as ferramentas digitais (tecnologias) com a aprendizagem, acentuamos que a Base Nacional Curricular Comum (BNCC), no que se refere à utilização de cultura digital, tecnologias e pensamento computacional, corrobora o fazer educacional dentro dessa perspectiva, garantindo o desenvolvimento e a aplicação de tais conceitos/ferramentas associadas ao desdobramento educacional (PINTO; NASCIMENTO, 2018).

As tecnologias assistivas voltadas para as pessoas com impedimento auditivo são variadas, como as ferramentas de tradução automática virtuais: Prodeaf, comprado pela plataforma Hand Talk; e VLivras e Rybená, tecnologias assistivas que, além da tradução automática, têm a função de acessibilizar o conteúdo para outros tipos de impedimentos e podem auxiliar a comunicação entre as pessoas com impedimento auditivo e a sociedade.

Mirailh et al., (2018) mapeou os aplicativos destinados ao ensino de Libras disponíveis na internet e muitos são usados para o ensino do português como segunda língua, mas esses autores concluíram que eles foram pensados na lógica do ouvinte, pois não atendem a dois parâmetros básicos da língua de sinais: a orientação do sinal e o movimento. A partir desse levantamento, os autores recomendam a elaboração do conteúdo a ser ensinado no formato de vídeo para se adequar à forma de aprendizagem mais favorável para aprendizes surdos, já que todos esses recursos impulsionam o processo de aquisição da leitura e da escrita.

3.1 O letramento visual como fator fundamental para o desenvolvimento do discente com impedimento auditivo

Considerando o investimento em uma sociedade democrática, faz-se necessário pensar na efetivação da oferta de escolas bilíngues (Libras/Português) em todo território brasileiro, de modo que as unidades escolares sejam providas com materiais visuais específicos, avaliações diferenciadas e estratégias visuais, além de professores bilíngues que conheçam as necessidades linguísticas dos discentes com impedimento auditivo e possam investir em seu desenvolvimento. Tendo em vista que a acessibilidade é um direito do discente com impedimento auditivo, concordamos com o artigo 27 da - Lei Brasileira de Inclusão (LBI) que diz:

Art. 27. A educação constitui direito da pessoa com deficiência, assegurados sistema educacional inclusivo em todos os níveis e aprendizado ao longo de toda a vida, de forma a alcançar o máximo desenvolvimento possível de seus talentos e habilidades físicas, sensoriais, intelectuais e sociais, segundo suas características, interesses e necessidades de aprendizagem (BRASIL, 2015). 
Elegemos a instituição escolar como um dos ambientes responsáveis por esse processo de aquisição de conceitos em diferentes áreas de conhecimento, e temos que considerar todos os elementos constitutivos desse ambiente como fundamentais para promover $o$ desenvolvimento cognitivo, social e psicológico dos alunos com impedimento auditivo.

Entendemos por ambiente de letramento visual, o ambiente físico educacional, formal e/ou informal, como por exemplo: uma sala de aula com a exposição de diversas informações em livros, jornais, revistas, legendas, entre outros. E os espaços informais que seriam os museus, bancas de jornais, espaços ricos em cartazes, avisos, textos, símbolos e ícones posicionados no espaço.

Faz-se necessário compreender que os discentes com impedimento auditivo necessitam de materiais bilíngues que estimulem o conhecimento de forma significativa. Esses materiais devem promover acesso às informações necessárias para 0 seu desenvolvimento cognitivo, social e emocional. Nesse contexto, percebemos que há necessidade de repensar o ensino em uma perspectiva bilíngue na educação das pessoas com impedimento auditivo. As estratégias e práticas pedagógicas precisam estar inseridas em contextos bilíngues visuais e significativos, de maneira a oportunizar constantemente as práticas sociais de leitura e escrita. Sendo assim, Bandini, Oliveira e Souza (2006, p.56) afirmam:

\footnotetext{
[...] Este fato sugere que investimentos em programas de Educação Infantil dentro de uma perspectiva escolar, voltada para o contato com material letrado, podem ser efetivos em auxiliar crianças surdas usuárias de Libras a verem-se como futuros leitores e escritores, e facilitar o processo de aquisição de leitura e escrita, mesmo quando elas são provenientes de classes sociais mais baixas, filhas de pais semianalfabetos (BANDINI, OLIVEIRA e SOUZA, 2006, p.56).
}

As habilidades e competências que nós, professores, devemos desenvolver nos discentes, que envolvem o letramento visual, partem, inicialmente, de seu conhecimento e do seu processo de aquisição de língua, seguindo a perspectiva de que a cognição se desenvolve por meio do uso desta língua e todos precisam ser expostos a situações dialógicas significativas, que os instiguem e possibilitem a elaboração do pensamento, consequentemente, internalizando novos conceitos (FERREIRA et al., 2020).

A partir de pesquisas como de: Fernández (1996), Ferreira et al. (2020) e Esteves et al., (2020), as quais mencionam que o português escrito pode ser plenamente adquirido por discentes com impedimento auditivo, quando é utilizada uma metodologia adequada, ou seja, o ensino não deve ser baseado em métodos tradicionais de alfabetização que priorizam a relação fonema/grafema e privilegiam a identificação de sons para compreensão da escrita e da leitura.

Fernandes (2003), Esteves et al., 2020 e Ferreira et al., (2020) comprovam que a aquisição de leitura e escrita de discentes com impedimento auditivo deve acontecer por meio de experiências significativas que se estabeleçam por meio do uso da língua de sinais e trocas de informações visuais, considerando a utilização de recursos imagéticos e trocas visuais com o meio em que o discente participa. Para Taglieber (apud QUADROS, 1997): 
A compreensão da leitura favorece o aprendizado de uma língua, mas ela depende de conhecimento prévio do leitor, de sua bagagem linguística e de mundo. O professor deve motivar a leitura, explicando antecipadamente o vocabulário e estruturas mais difíceis e qual a finalidade do texto (apud QUADROS, 1997, p. 94-95).

Naturalmente, a função da língua oral na sociedade é a comunicação, tendo ela a capacidade de internalizar o processo de aquisição/uso de conhecimento. Para a pessoa com impedimento auditivo, compreendemos a relação de ícone (imagem) e escrita, como processo de internalização e conceituação significativa de língua de sinais. São questões como as descritas acima que enfatizam o uso do letramento visual sob a perspectiva da surdez. É a partir de práticas educacionais que consideram a visualidade que os professores bilíngues de discentes com impedimento auditivo devem atuar para o desenvolvimento $\mathrm{e} o$ aperfeiçoamento do uso/prática do português como segunda língua (L2) para que se torne uma ação significativa.

Segundo Magda Soares (2014), a prática do letramento consiste em desenvolver habilidades no uso da leitura e escrita de forma contextualizada com sua realidade e práticas sociais. Assim, o letramento para essas pessoas agrega a dimensão de dar acessibilidade às informações e oportunidade de interação social.

Ferreira-Brito (1993) aponta as línguas de sinais como única modalidade de língua que permite à pessoa com impedimento auditivo desenvolver plenamente seu potencial linguístico e cognitivo, oferecendo-lhes possibilidades de socialização até aí impedidas pela defasagem em comparação à língua dos ouvintes (Ferreira-Brito; 1993, p.44).

Para que o letramento visual bilíngue (Libras/Português escrito) ocorra, faz-se necessário que os conhecimentos contidos no campo imaginário sejam inseridos, significativamente, no contexto das relações estabelecidas, por meio da língua de sinais. Pois, para as pessoas com impedimento auditivo, a imagem tem que fazer relação com seu contexto visual e informativo para que haja o desenvolvimento e a compreensão do conceito e de sua língua. Peixoto (2006) menciona que:

[...] as crianças surdas vivenciam um processo de (re) construção da escrita que, em muitos aspectos, é semelhante ao que é vivido pela criança ouvinte; ou seja, caminham de uma perspectiva inicial mais subjetiva, na qual a escrita não representa o nome das coisas e sim as próprias coisas, evoluindo para uma compreensão de escrita como representação da linguagem (PEIXOTO, 2006, p.211).

O estímulo para o desenvolvimento da escrita dessas crianças com impedimentos auditivos é um fator que necessita de atenção, de trabalho direcionado e colaborativo, envolvendo a família e a escola no trabalho pedagógico. Lacerda et al., (2011) menciona que:

A escola pode colaborar para exploração das várias nuances da imagem, signo, significado e semiótica visual na prática educacional cotidiana, oferecendo subsídios para ampliar os "olhares" aos sujeitos surdos e à sua capacidade de captar e compreender o "saber" e a "abstração" do pensamento imagético (LACERDA, et al., 2011, p.108). 
Concordamos com Lacerda et al. (2011): quanto mais estímulo, melhor será o resultado na aprendizagem dos conteúdos pelos discentes com impedimento auditivo.

De acordo com Procópio e Souza (2009), para que a prática do letramento visual seja introduzida na educação com a finalidade de promover e desenvolver o conhecimento linguístico e de mundo desses discentes, é de extrema importância que aquele seja incorporado ao currículo das unidades de ensino, a fim de que as intervenções educacionais aconteçam em diversos momentos e maneiras. Segundo Machado (2009) temos que refletir sobre a potencialidade que a Libras tem para a pessoa com impedimento auditivo e sobre o reflexo dessa potencialidade no planejamento de estratégias didáticas e na produção de materiais adequados.

3.2 Estratégias, recursos e adaptações necessárias para que o discente com impedimento auditivo tenha acesso aos conteúdos escolares

Para que o letramento visual ocorra de forma significativa, estimulando a habilidade de leitura/interpretação e o devido registro em português na modalidade escrita (L2), é indispensável a utilização de materiais que estimulem os alunos com impedimento auditivo à realização de produções autônomas.

Atualmente, vem crescendo o número de materiais didáticos e informativos que contemplam uma abordagem bilíngue, como por exemplo: a cartilha sobre bullying dos autores Barros (2018), o livro infantil de divulgação do ciclismo e benefícios da biotecnologia na promoção da saúde dos autores Portella et al. (2018), e o projeto FolcloLibras com cantigas de roda acessíveis para as pessoas com impedimento auditivo dos autores Ferreira et al. (2020).

Percebemos um crescimento considerável, no mercado comercial, de algumas iniciativas de produção de produtos pedagógicos com o uso de desenhos ou de imagens que remetem à língua de sinais. No entanto, os materiais visuais adequados para o ensino do português como segunda língua ainda não são produzidos com a mesma proporção com que são disponibilizados para os ouvintes (Portella et al., 2018). Estamos considerando que os materiais bilíngues devem ser pensados propriamente para os discentes com impedimento auditivo, haja vista que as adaptações nem sempre atendem às especificidades linguísticas desse grupo.

Atentando para o exposto até aqui, podemos afirmar, através da prática diária de sala de aula, que o discente não deve ser exposto de maneira excessiva a imagens e legendas, mas deve ser levada em conta a necessidade de uma exposição planejada e contextualizada, proporcionando ao discente boa compreensão e assimilação dos conceitos em ambas as línguas (Português/Libras), dando preferência para a elaboração de materiais que tenham a participação efetiva dos alunos.

Como dissemos anteriormente, para produzir os materiais bilíngues para o ensino da pessoa com impedimento auditivo é imprescindível considerar o uso de imagens em contexto social. Por exemplo: não basta que o discente aprenda a escrever a palavra "bicicleta", mas é preciso que ele saiba para que serve a bicicleta, quais os cuidados necessários ao utilizá-la, etc. As informações escolares precisam adquirir significado e produzir novos sentidos, pois de acordo com Lacerda et al. (2011) 
Uma imagem suscita o leitor a reflexões de situações, da sociedade, que, ao mesmo tempo em que as capta neste meio, são também reflexos da mesma, revelando elementos de exclusão social, consumismo, abandono, felicidade, entre outros da nossa sociedade (LACERDA, et al., 2011, p.105).

Contextualizar e levantar questões para que os discentes possam refletir sobre a realidade na qual estão inseridos é uma prática necessária para que aconteça a inclusão. Os professores, ao pensarem em proporcionar acesso aos conteúdos, devem respeitar a abordagem bilíngue como orientação pedagógica e garantir o acesso ao conhecimento, ao invés de centrarem suas preocupações em adaptações de aulas e materiais pensados somente para discentes ouvintes.

Ao utilizar materiais que contenham músicas com sinalização em Libras ou vídeos com pequenas janelas de tradução em Libras, estamos utilizando materiais com estratégias de adaptação mais adequadas para alunos já fluentes ou adultos. Nesse modelo de atividade, a criança com impedimento auditivo opta pela observação da imagem ou da sinalização, não tendo acesso integral à informação, já que, ainda em processo de aquisição linguística, não tem maturidade para utilizar materiais adaptados com aproveitamento satisfatório.

Quando consideramos a possibilidade de adaptação de material é porque este foi pensado com outro propósito e será reajustado para tentar atender outro objetivo, o ensino de Português. As propostas pedagógicas devem partir das demandas visuais e serem pensadas, desde o início, para atenderem às necessidades linguísticas desses discentes. Ao pensar em atividades para alunos com impedimento auditivo, é essencial pensar em transmitir conceitos e ampliar o universo vocabular deles, de maneira contextualizada, por meio da língua de sinais e do uso de imagens. Esses discentes não irão desenvolver habilidades de leitura e escrita por meio da relação fonema e grafema. Nesse contexto, cada palavra é uma imagem e cada imagem precisa ser internalizada em sua memória visual. Esse processo de internalização das palavras e estruturas frasais em português não acontece tão rapidamente e faz-se necessário que o discente seja exposto, muitas vezes, a um mesmo vocabulário, de formas e estratégias diversificadas para que a aprendizagem não se torne um processo cansativo e desestimulante.

No entanto, não estamos dizendo que isso deva acontecer por meio da cópia de vocabulário solto e descontextualizado. É preciso que se utilize metodologia adequada e que a pessoa com impedimento auditivo vivencie diversas situações de exposição e utilização de um mesmo vocabulário para que ele possa internalizar a imagem da palavra e ao mesmo tempo consiga utilizá-la de maneira consciente em frases e textos significativos.

De acordo com Quadros e Schmiedt (2006, p. 42-43), a leitura precede a escrita e, para tal, no contexto do discente com impedimento auditivo, a leitura passa por diversos níveis:

1) Concreto - sinal: ler o sinal que refere coisas concretas, diretamente relacionadas com a criança.

2) Desenho - sinal: ler o sinal associado com o desenho que pode representar o objeto em si ou a forma da ação representada por meio do sinal.

3) Desenho - palavra escrita: ler a palavra representada por meio do desenho relacionada com o objeto em si ou a forma da ação representado por meio do desenho na palavra.

4) Alfabeto manual - sinal: estabelecer a relação entre o sinal e a palavra no português soletrada por meio do alfabeto manual.

5) Alfabeto manual - palavra escrita: associar a palavra escrita com o alfabeto manual. 
6) Palavra escrita no texto: ler a palavra no texto (QUADROS; SCHMIEDT; 2006, p. 42-43).

Na medida em que a pessoa com impedimento auditivo for adquirindo a capacidade de ler e compreender os textos, ela também vai adquirindo a capacidade de escrever textos. A escrita pode ser estimulada por meio de registros das atividades feitas em sala de aula intermediadas pela língua de sinais.

Acerca da acessibilidade visual aos conteúdos escolares por parte dos discentes com impedimentos auditivos, podemos considerar também o potencial do uso da internet e das tecnologias em geral para promover a aquisição de conhecimento. As tecnologias, em virtude das diversas possibilidades, contribuem de forma significativa e positiva para que muitos conceitos sejam ilustrados e para que as pessoas com impedimento auditivo possam se apropriar do aprendizado da Libras mais facilmente (MARTINS; BRAZ 2017).

Para além dos registros das atividades escolares, outra maneira de estimular a escrita é ter ao alcance de seus olhos um banco de imagens identificadas que possam ser acessadas sempre que necessário. Esse banco de palavras pode estar disponível como um dicionário, construído junto com os discentes em forma de caixa com cartelas de imagens, ou como murais de vocabulário, cadernos de registros, computador com glossários em vídeo, entre tantas outras estratégias. O mais importante é garantir ao discente a possibilidade de consultar um material adequado sempre que precisar. Esses recursos podem transmitir segurança para escrever e, na medida em que forem adquirindo experiência, os próprios discentes deixarão de recorrer aos apoios disponíveis. A grande questão é não deixar o discente com medo de escrever porque não tem elementos suficientes para colocar no papel.

Ainda de acordo com Quadros e Schmidt (2006), a pessoa com impedimento auditivo formula o seu pensamento por imagens e, a princípio, não se deve ter preocupação excessiva com a estrutura formal da língua portuguesa. É importante que o discente se sinta seguro em expressar o pensamento em língua de sinais para que, depois, comece a se arriscar em produções independentes escritas.

Ao iniciar seu processo de escrita, essas crianças tenderão a escrever palavras isoladas ou montar frases de acordo com a estrutura da língua de sinais. Isso ocorrerá porque se expressarão na estrutura em que pensam, algo muito comum e que acontece durante a aprendizagem de qualquer estudante de segunda língua, com impedimento auditivo ou não. Esse processo é natural, ainda mais se levarmos em conta que as duas línguas envolvidas são de modalidades diferentes. Ou seja, a pessoa com impedimento auditivo pensa em língua de sinais, que é gestual-visual, e terá que escrever em português, que é uma língua oral-auditiva.

Os materiais didáticos e recursos existentes, elaborados por professores que desconhecem as singularidades linguísticas das pessoas com impedimento auditivo, têm oferecido recursos propostos a partir do desenho de "mãozinhas" substituindo cada letra da língua portuguesa, tomando isso como suficiente para representar a língua de sinais. No entanto, não podemos nos limitar a esses materiais que fazem referência à língua de sinais de forma tão simplista, mesmo porque a língua de sinais requer movimento. Os desenhos estáticos não possibilitam uma referência adequada aos parâmetros da Libras, sendo que, além da representação de mãos (que isoladamente não são suficientes), devemos considerar as propostas visuais diversas facilitadas pelo acesso às diferentes ferramentas tecnológicas.

Muitos materiais visuais podem ser utilizados como: maquetes, cartelas com imagens, jogos imagéticos, pranchas de comunicação, filmes em DVD, desenhos animados, 
teatralização, livros de história ilustrados, materiais escritos, uso de aplicativos, jogos desplugados e plugados, entre outros.

As atividades desplugadas podem ser utilizadas para desenvolver as habilidades voltadas para o letramento visual com etapas determinadas pela Taxonomia de Bloom (1956) que são: lembrar, entender, aplicar, analisar, sintetizar e criar. Assim, a pessoa com impedimento auditivo quando decompõe (que é a capacidade de dividir um problema em partes menores, facilitando a resolução de um problema complexo); estabelece um padrão (que é a habilidade de reconhecer padrões, separando em grupos de similaridades para identificar comportamentos específicos), abstrai (ao focar no que realmente importa, deixando de lado os detalhes para encontrar soluções mais específicas para o problema) e utiliza o pensamento algoritmo (que é a capacidade de desenvolver e seguir uma série de passos ordenados com o objetivo de chegar à uma solução para um problema) (RAMOS, 2014).

Sugerimos que as TIC sejam um recurso utilizado de forma efetiva para incentivar o letramento visual, possibilitando a aproximação entre um meio que possibilite o processo de inclusão, de socialização do conhecimento e de exercício da cidadania. Elas devem ultrapassar a simples utilização de entretenimento para se tornarem equipamentos que possam proporcionar o uso eficaz, a fim de promover o crescimento humano.

O importante não é apenas o tipo de material, mas a maneira como estes serão utilizados de acordo com uma proposta bilíngue. Não adianta contar com materiais visuais ricos e diversificados se não forem utilizados em contexto bilíngue, por profissionais bilíngues e com estratégias adequadas à aquisição de conceitos por discentes com impedimento auditivo.

Para garantir que o letramento visual seja significativo, é fundamental a qualidade combinada desses recursos, pois, se bem trabalhados, possibilitam a aquisição de conceitos e entendimento do discente. Assim, cabe aos professores um planejamento prévio para que as interações sejam adequadas e estimulem o desenvolvimento linguístico e conceitual dos estudantes. Frisando que uma das ferramentas que poderá auxiliar o trabalho com este público são atividades mediadas pelas tecnologias da informação e da comunicação.

\section{Considerações finais}

Esta pesquisa nos levou a refletir sobre a educação das pessoas com impedimento auditivo considerando a legislação e políticas públicas que orientam uma educação bilíngue, inserida em escolas inclusivas. Desafiou-nos a pensar em possibilidades de viabilizar uma educação bilíngue em espaços escolares em que a maioria da comunidade é ouvinte e não domina o uso da língua de sinais.

Refletimos sobre a importância da aquisição da língua de sinais como primeira língua dos indivíduos com impedimento auditivo e da língua portuguesa na modalidade escrita como segunda língua, considerando a necessidade de inserção da língua de sinais nas escolas inclusivas sob uma perspectiva de respeito aos direitos linguísticos dos discentes. $\mathrm{Na}$ intenção de visibilizar a língua de sinais em contexto escolar, estudamos sobre o letramento visual como principal via de inclusão desses discentes na escola e na sociedade.

Dessa maneira, reafirmamos que o tempo da imagem é o tempo da palavra, pois exige do professor bilíngue a maneira apropriada de criar materiais para os discentes, fomentando e 
apresentando conceitos de maneira que sejam internalizados e externalizados significativamente com autonomia.

Afirmamos, neste artigo, a importância de uma escola que atenda às necessidades de todos, mas destacamos que a educação das pessoas com impedimento auditivo numa perspectiva bilíngue não deve se restringir ao uso de duas línguas, mas à efetivação de práticas visuais de letramento, inseridas em uma afirmação social e política da educação.

Entendendo que o sistema educacional ainda não dispõe de um número significativo de profissionais formados para educação bilíngue (português /Libras) e diante da ausência de acessibilidade às informações, às estratégias e aos recursos, assim como a estruturas pedagógicas, percebemos que necessitamos ampliar a produção de materiais didáticos bilíngues para os discentes, pois só assim poderemos, de fato, afirmar que estamos oportunizando a equidade.

Sendo assim, concluímos que o potencial visual dos discentes com impedimento auditivo deve ser levado em conta para aprendizagem significativa e há necessidade de formação de profissionais bilíngues para atender suas demandas linguísticas. Mas não basta acreditar que o uso indistinto de estímulos por meio de imagens será suficiente para acessibilizar o conhecimento aos discentes. A criação e a utilização de materiais visuais específicos compreende pensar a educação a partir da lógica visual. Precisamos nos afastar da ideia de adaptação de aulas e materiais para dar mais atenção à elaboração de aulas específicas que realmente contemplem a todos.

\section{Referências}

BANDINI, Heloísa Helena Motta; OLIVEIRA, Claudia Lessa de Azevedo Corrêa de; SOUZA, Érika Costa de. Habilidades de leitura de pré-escolares deficientes auditivos: letramento emergente. Paidéia, Ribeirão Preto, v.16, n. 33, p.51-58, 2006. Disponível em: https://www.scielo.br/pdf/paideia/v16n33/08.pdf. Acesso em: 5 fev. 2021.

BARROS, Rodrigo dos Santos. Combate ao Bullying: uma proposta de sensibilização através de uma cartilha informativa bilíngue para alunos surdos. Orientadora: Ruth Maria Mariani Braz. Dissertação (Mestrado profissional em Diversidade e Inclusão). Instituto de Biologia. Universidade Federal Fluminense. Niterói: Rio de Janeiro, 2018.

BELL, Tin; WITTEN, Ian H.; FELLOWS, Mike. Computer Science Unplugged: Ensinando Ciência da Computação sem uso do computador. Tradução: Luciano Porto Barreto, 2011. Disponível em:

https://classic.csunplugged.org/wpcontent/uploads/2014/12/CSUnpluggedTeachers-portugues e-brazil-feb-2011.pdf. Acesso em: 4 mar. 2021.

BRASIL. [Constituição (1988)] Constituição da República Federativa do Brasil de 1988, 40 ed. São Paulo: Saraiva, 2007. Brasília, Distrito Federal. Disponível em: http://www.planalto.gov.br/ccivil_03/constituicao/constituicao.htm. Acesso em: 21 fev. 2021.

BRASIL. Lei No 9394/96, de 20 de dezembro de 1996. Dispõe sobre Diretrizes e Bases da Educação Nacional, LDB, Ministério da Educação. Brasília, Distrito Federal. Disponível em: http://www.planalto.gov.br/ccivil_03/leis/19394.htm. Acesso em: 21 fev. 2021. 
BRASIL. Lei $\mathbf{N}^{\mathbf{0}}$. 10.436, de 24 de abril de 2002. Dispõe sobre a Língua Brasileira de Sinais - LIBRAS e dá outras providências, Ministério da Educação. Secretaria de Educação Especial. Brasília, Distrito Federal. Disponível em:

http://www.planalto.gov.br/ccivil_03/leis/2002/110436.htm. Acesso em: 21 fev. 2021.

BRASIL. Decreto $n^{\circ} 5.626$, de 22 de dezembro de 2005. Regulamenta a Lei $n^{\circ} 10.436$, de 24 de abril de 2002, que dispõe sobre a Língua Brasileira de Sinais - Libras, e o art. 18 da Lei ${ }^{\circ}$ 10.098, de 19 de dezembro de 2000. Diário Oficial da União, Brasília, Distrito Federal, Disponível em:http://www.planalto.gov.br/ccivil_03/_ato2004-2006/2005/decreto/d5626.htm. Acesso em: 21 fev. 2021.

BRASIL. Lei $\mathbf{N}^{\mathbf{0}}$ 13.146, de 6 de julho de 2015. Dispõe sobre a Lei Brasileira de Inclusão da Pessoa com Deficiência. Brasília, Distrito Federal. Disponível em: http://www.planalto.gov.br/ccivil_03/_Ato2015-2018/2015/Lei/L13146.htm, Acesso em: 20 fev. 2021.

ESTEVES, Ângela Simone Mattos, MARIANI BRAZ, Ruth Maria e SILVA, Dagmar de Mello. As multiplicidades rizomáticas do sujeito-surdo-social-plural no processo de letramento bilíngue. Revista Educação Especial, n.33, p. 77-1, 2020. ISSN 1984-686X. http://dx.doi.org/10.5902/1984686X42625. Disponível em:

https://periodicos.ufsm.br/educacaoespecial/article/view/42625/html. Acesso em: 3 mar. 2021.

FERNANDES, Sueli. Educação bilíngue para surdos: identidades, diferenças, contradições e mistérios. Tese Doutorado - UFPR. Curitiba, 2003. Disponível em:

http://acervodigital.ufpr.br/bitstream/handle/1884/24287/T\%20-\%20FERNANDES,\%20SUE LI\%20DE\%20FATIMA\%20.pdf?sequence=1. Acesso em: 21 fev. 2021.

FERNANDES, Sueli. e MOREIRA Laura Ceretta Políticas de educação bilíngue para surdos: o contexto brasileiro. Educar em Revista, Curitiba, Brasil, Edição Especial n. 2, p. 51-69, 2004. Disponível em: http://revistas.ufpr.br/educar/article/view/37014/23096. Acesso em: 21 fev. 2021.

FERNANDEZ, María Del Pilar. Reflexiones sobre la escritura y la alfabetización de los niños surdos. Revista de Logopedia, Fonología y Audiología. v. XVI, n. 2, p. 79-85, 1996. ISSN 0214-4603. Disponível em: https://dialnet.unirioja.es/servlet/articulo?codigo $=5339011$.

Acesso em: 3 mar. 2021.

FERREIRA, Alessandra Teles Sirvinskas; BRAZ, Ruth Maria Mariani; DE FARIAS MELO, Isabel Cristina Nonato. FolcloLibras: cantigas de roda acessíveis para surdos. Conhecimento \& Diversidade, v. 12, n. 26, p. 116-136, 2020. Disponível em:

https://revistas.unilasalle.edu.br/index.php/conhecimento_diversidade/article/view/6780. Acesso em: 3 mar. 2021.

FERREIRA-BRITO, Lucinda. Integração social \& educação de surdos. Rio de Janeiro: Babel, 1993.

GESSER, Audrei. LIBRAS? Que língua é essa? Crenças e preconceitos em torno da língua de sinais e da realidade surda. São Paulo: Parábola, 2009.

GIL, Antônio Carlos. Como elaborar projetos de pesquisa, São Paulo: Atlas, 2002. 
GLAT, Rosana; BLANCO, Leila de Macedo Varela. Educação Especial no contexto de uma educação inclusiva. In: GLAT, R. (org). Educação inclusiva: cultura e cotidiano escola. (Coleção Questões atuais em Educação Especial, v. VI). Rio de Janeiro: Editora Sete Letras, p.15-35, 2007. Disponível em:

http://professor.pucgoias.edu.br/SiteDocente/admin/arquivosUpload/17962/material/Educa\% C3\%A7\%C3\%A3o\%20especial\%20no\%20contexto\%20de $\% 20$ uma $\% 20$ educa $\%$ C3\%A7\%C3 $\%$ A3o\%20inclusiva.pdf. Acesso em: 2 mar. 2021.

LACERDA, Cristina Broglia Feitosa de.; SANTOS, Lara Ferreira dos; CAETANO, Juliana Fonseca. Estratégias metodológicas para o ensino de discentes surdo. In: Língua brasileira de sinais: Libras uma introdução. São Paulo: UAB-UFSCar, p.103-118, 2011. Disponível em: https://ceiq4.webnode.com/_files/200001670-19ceelac87/2.pdf. Acesso em: 3 mar. 2021.

LU, James; FLETCHER, George. Pensando em pensamento computacional. In: Anais do 40 Simpósio Técnico da ACM sobre Educação em Informática, p. 260-264, mar. 2009. ISBN 978-1-60558-183-5. DOI https://doi.org/10.1145/1508865.1508959. Disponível em: https://dl.acm.org/doi/abs/10.1145/1508865.1508959. Acesso em: 3 mar. 2021.

MACHADO, Paulo Cesar. Diferença cultural e educação bilíngue: as narrativas de professores surdos sobre questões curriculares. Orientador: Ronice Muller Quadros. Tese (Doutorado em Educação) - Universidade Federal de Santa Catarina. Florianópolis, 2009. Disponível em:

https://repositorio.ufsc.br/bitstream/handle/123456789/92494/266573.pdf?sequence=1. Acesso em: 3 mar. 2021.

MARIANI BRAZ, Ruth Maria. Atividades para o ensino de ondas sonoras aos discentes surdos: uma proposta inclusiva. Revista Aleph, p. 30, 2018. ISSN 1807-6211. DOI https://doi.org/10.22409/revistaleph.v0i30.39256. Disponível em:

https://periodicos.uff.br/revistaleph/article/view/39256. Acesso em: 3 mar. 2021.

MARTINS, Gabriel Pigozzo Tanus Cherp; BRAZ, Ruth Maria Mariani. Língua e Tecnologia: a Libras na Web. Juiz de Fora: Editar, 2017.

MEIRELES, Rosana Maria do Prado Luz. Políticas de Inclusão e Práticas Pedagógicas na Educação de Discentes Surdos: Programa de Bilinguismo de Niterói/RJ. Orientadora: Waldelúcia Alves da Costa. Tese (Doutorado em Educação) Faculdade de Educação da Universidade Federal Fluminense. Niterói (RJ), 2014.

MIRAILH, Sarah; MARIANI, Ruth Mariani e LETA Fabiana Rodrigues; Mapeamento dos aplicativos para o ensino de Libras. Rio de Janeiro: Abdin/Perse, 2018.

OLIVEIRA. Sara Texto visual e Leitura crítica: o dito, o omitido, o sugerido. Linguagem \& Ensino, Pelotas, v.9, n.1, p. 15-59, jan./jun. 2006. ISSN 1983- 2400. DOI https://doi.org/10.15210/rle.v9i1.15626. Disponível em: https://periodicos.ufpel.edu.br/ojs2/index.php/rle/article/view/15626. Acesso em: 3 mar. 2021.

PAPERT, Seymour; VALENTE, Jose Armando; BITELMAN, Beatriz. Logo: computadores e educação. São Paulo: Brasiliense, 1980.

PETITTO, Laura Ann; MARENTETTE, Paula. Babbling in the manual mode: Evidence for the ontogeny of language. Science, v. 251, n. 5000, 1991. ISSN 1493-1496. DOI 
10.1126/science.2006424. Disponível em:

https://science.sciencemag.org/content/251/5000/1493. Acesso em: 3 mar. 2021

PEIXOTO, Renata. Castelo Algumas considerações sobre a interface entre a Língua Brasileira de Sinais (LIBRAS) e a Língua Portuguesa na construção inicial da escrita da criança surda.

Caderno CEDES, v. 26, n. 69, p.205-229, 2006. ISSN 1678-7110 DOI

https://doi.org/10.1590/S0101-32622006000200006. Disponível em:

http://www.scielo.br/scielo.php?script=sci_arttext\&pid=S010132622006000200006\&lng=pt\& nrm=iso. Acesso em: 3 fev. 2021.

PINTO, Sérgio Crespo Coelho da Silva; NASCIMENTO, Gisele Soares Rodrigues O pensamento computacional e a nova sociedade. In: VALENTE, José Armando; FREIRE, Fernanda Maria Pereira; ARANTES, Flávia Linhalis (org.). Tecnologia e educação: passado, presente e o que está por vir. Campinas: NIED/UNICAMP, v. 1, p. 302-322, 2018. ISBN 978-85-88833-10-4 Disponível em:

https://www.nied.unicamp.br/wp-content/uploads/2018/11/Livro-NIED-2018-final.pdf. Acesso em: 3 mar. 2021.

PORTELLA, Sandro, Medeiros. A utilização do livro de história infantil bilíngue português/libras - no contexto educacional: divulgação do ciclismo e benefícios da biotecnologia na promoção da saúde. Orientado por: Dra. Dilvani Oliveira Santos da Universidade Federal Fluminense e coorientado pela Dra. Ruth Maria Mariani Braz. Dissertação (Mestrado do Curso em Biotecnologia e Ciências) Instituto de Biologia. Universidade Federal Fluminense. Niterói (RJ), 2018.

PRADO, Rosana; MACEDO, Jeane Lisa Marques Ferraz de. Aquisição de línguas por crianças surdas: a importância do letramento visual. RevistAleph, ano XIII, n. 26, p.140-154, 2016. ISSN 1807- 6211. DOI https://doi.org/10.22409/revistaleph.v0i26.39155. Disponível em: https://periodicos.uff.br/revistaleph/article/view/39155. Acesso em: 3 mar.2021.

QUADROS, Ronice Muller de. Educação de surdos a aquisição da linguagem. Porto Alegre: Editora Artes Médicas Sul Ltda, 1997.

QUADROS, Ronice Muller de; KARNOPP, Lodenir Língua de sinais brasileira: estudos linguísticos. Porto Alegre: Artmed, 2004.

QUADROS, Ronice Muller de; SCHMIEDT, Magali. Ideias para ensinar português para surdos. Brasília: MEC; SEESP, 2006. Disponível em:

https://www.gov.br/mec/pt-br/media/publicacoes/semesp/port_surdos.pdf. Acesso em: 3 mar. 2021.

QUADROS, Ronice Muller; CRUZ, Carina Rabelo Língua de sinais: instrumentos de avaliação. Porto Alegre: Artmed, 2011.

RAMOS, Henrique de Almeida. Pensamento Computacional na Educação Básica: uma proposta de aplicação pedagógica para alunos do quinto ano do Ensino Fundamental do Distrito Federal. Brasília: UnB, 2014.

SASSAKI, Romeu. K. Inclusão. Construindo uma sociedade para todos. 7. ed. Rio de Janeiro: WVA, p.3, 2006. 
SOARES. Magda. Alfabetização e letramento: caderno do professor. Belo Horizonte: CEALE/UFMG, 2005.

SOARES Magda. Letramento e alfabetização: as muitas facetas. Revista Brasileira De Educação. Rio de Janeiro: n. 25, p. 5-17, 2014. ISSN 1809-449X. DOI https://doi.org/10.1590/S1413-24782004000100002. Disponível em: https://www.scielo.br/scielo.php?pid=S141324782004000100002\&script=sci_abstract\&tlng= pt. Acesso em: 3 mar. 2021.

SOARES, Magda Letramento: Um tema em três gêneros. 3 ed. 3 reimp. Belo Horizonte: Autêntica, 2016.

PROCÓPIO, Renata Bittencourt e SOUZA, Patrícia Nora. Os recursos visuais no ensino-aprendizagem de vocabulário em língua estrangeira. Maringá, v. 31, n. 2, p.139-146, 2009. ISSN 1983-4683. DOI https://doi.org/10.4025/actascilangcult.v31i2.8421. Disponível em: https://periodicos.uem.br/ojs/index.php/ActaSciLangCult/article/view/8421. Acesso em: 3 mar. 2021.

VYGOTSKY, Lev Semionovitch. Pensamento e linguagem. São Paulo: Martins Fontes, 2005.

XAVIER, Ana Paula., MARTINS, Gabriel. Pigozzo Tanus. Cherp., COUTINHO, Cláudia Mara Lara; MARIANI, Ruth Maria. Educação bilíngue de surdos: uma proposta de implementação na rede municipal de educação de Juiz de Fora/MG. Revista Letras Raras, v. 5, n. 1, 27-34, 2016. ISSN 2317-2347. DOI http://dx.doi.org/10.35572/rlr.v5i1.576.

Disponível em: http://revistas.ufcg.edu.br/ch/index.php/RLR/article/view/576. Acesso em: 03 jan. 2021.

WING, Jeannette Marie. Computational thinking. Communications of the ACM, v. 49, n.3, p. 33-35, 2006. DOI 10.1145/1118178.1118215. Disponível em:

https://www.cs.cmu.edu/ 15110-s13/Wing06-ct.pdf . Acesso em: 3 mar. 2021.

Recebido em março de 2021.

Aprovado em maio de 2021. 